\title{
Affect and persuasion: Mood effects on the processing of message content and context cues and on subsequent behaviour
}

\author{
GERD BOHNER, KIMBERLY CROW and \\ HANS-PETER ERB \\ Universität Mannheim, FRG \\ AND \\ NORBERT SCHWARZ \\ Zentrum für Umfragen, Methoden und Analysen \\ (ZUMA), Mannheim, FRG
}

\section{Abstract}

Two experiments are reported examining the impact of recipients'mood on the processing of simple, everyday persuasive communications and on subsequent behaviour. Consistent with the general assumption that affective states may inform an individual about the state of its current environment, it was found that positive (as compared to neutral or negative) mood reduced subjects' motivation to systematically process both content information and contextual cues. Specifically, Experiment 1 demonstrated that, in a field setting, the behaviour of subjects who had been put in a good mood was less likely to reflect differences in message content than the behaviour of neutral mood subjects. Experiment 2 replicated and extended these findings, showing that good mood subjects' behaviour was uninfluenced by content as well as context information, whereas bad mood subjects did make use of both types of information. Subjects's cognitive responses and evaluations paralleled the behavioural data. The results are discussed in terms of their compatibility with contemporary models of persuasion, and their implications for future research on mood and persuasion and on the interplay of affect and cognition in general are considered.

Addressee for correspondence: Dr Gerd Bohner, Universität Mannheim, Sozialpsychologie, A 5, D-6800 Mannheim 1, Federal Republic of Germany.

The reported research was supported by the Deutsche Forschungsgemeinschaft (Grants Str $264 / 2$ to Fritz Strack and Norbert Schwarz, and Schw 278/5 to Norbert Schwarz, Herbert Bless and Gerd Bohner). The two experiments reported were conducted by Gerd Bohner as part of his dissertation at the University of Heidelberg, under the supervision of Norbert Schwarz. The authors gratefully acknowledge stimulating discussions with Herbert Bless, Shelly Chaiken, Stefan Hormuth, and Fritz Strack. Thanks are due to Hansjörg Frenzel and Elke Schäfer, who served as confederates in Experiment 1. 


\section{INTRODUCTION}

The impact of affective states on the strategies that recipients use to process persuasive messages has recently received considerable research attention (see Schwarz, Bless and Bohner, 1991, for a review). The interest in this issue reflects that the cognitive processes involved in persuasion are reasonably well understood (see Eagly and Chaiken, in press; Petty and Cacioppo, 1986a, for reviews), rendering the processing of persuasive communications a fruitful, and social psychologically interesting, area for explorations of the interplay of affect and cognition in general. In the present paper, we will extend previous laboratory research by investigating the impact of recipients' mood states on their processing of simple persuasive communications in everyday life contexts. In doing so, we will contrast predictions derived from motivational and capacity explanations of affective influences on processing strategies. In addition, we will test rival hypotheses concerning mood effects on the use of non-content cues, derived from Petty and Cacioppo's (1986a,b) 'elaboration likelihood model' (ELM) and from Chaiken, Liberman and Eagly's (1989) 'heuristicsystematic model' (HSM).

\section{Processing persuasive communications}

Contemporary models of persuasion distinguish between two general 'modes' of attitude change. On the one hand, attitude change can be the result of recipients' careful and effortful evaluation of the available arguments and other useful information. Under these circumstances, the magnitude of change has been shown to be a function of the quality of the available evidence, especially message content, and is mediated by the valence of recipients' cognitive responses. This has been termed the 'central route' to persuasion (Petty and Cacioppo, 1981, 1986a,b) or 'systematic processing' (Chaiken, 1980, 1987; Chaiken et al., 1989). On the other hand, attitude change may occur without extensive processing of message content. Recipients may totally ignore the content of a message and still form a judgment, merely relying on some superficial context cue, such as the communicator's likeability (e.g. Petty, Cacioppo and Schumann, 1983), or using simplifying 'rules of thumb' like 'the more arguments, the better' (Chaiken, Axsom, Yates, Wilson, Hicks and Liberman, 1988). In this mode of attitude change, which has been labelled the 'peripheral route' to persuasion (Petty and Cacioppo, 1981, 1986a,b) or 'heuristic processing' (Chaiken, 1980, 1987; Chaiken et al., 1989), attitude change has been shown to be largely independent of argument quality.

Which of the two 'routes' or processing modes is used depends on recipients' motivation and ability to process the persuasive message. If both motivation and ability are high, the probability of systematic processing is increased. If either motivation or ability are low, heuristic processing may still provide an economic way of forming an attitude judgment. For instance, a person lacking the ability to carefully process message content because of external distraction, may still be able to form an attitude judgment on the basis of the communicator's credibility (e.g., Kiesler and Mathog, 1968).

\section{The impact of affective states}

While current theorizing on the interplay of affect and cognition suggests several different ways in which recipients' mood may influence persuasion within this general 
framework (see Petty, Cacioppo and Kasmer, 1988; Schwarz, Bless and Bohner, 1991, for an overview), the bulk of empirical evidence indicates that recipients' affective state influences the extent to which the content of a persuasive message is systematically processed. Specifically, positive affect during message exposure has been shown to decrease systematic processing, as compared to negative or neutral affect. Accordingly, subjects in an elated mood are typically less persuaded by strong arguments, but more persuaded by weak arguments, than subjects in a neutral or a mildly depressed mood (Bless, Bohner, Schwarz and Strack, 1990; Bless, Mackie and Schwarz, 1990; Innes and Ahrens, 1991; Mackie and Worth, 1989; Worth and Mackie, 1987).

Although this basic finding has been consistently replicated, different process assumptions have been offered to account for it, focusing either on mood-induced differences in recipients' motivation or on mood-related restrictions in processing capacity. Mackie and Worth (1989) hypothesized that positive mood should limit the cognitive capacity available for message processing by priming positive thoughts in memory, which are supposed to be more extensive and interconnected than negative or neutral thoughts (cf. Isen, 1987; Matlin and Stang 1979). Mackie and Worth (1989) predicted and found that offering subjects unlimited time to process a message increased good mood subjects' systematic processing of message content to a level that no longer differed from neutral mood subjects' processing. Under processing time restrictions, however, mood differences were obtained. This was interpreted as evidence for the mediating role of cognitive capacity in mood effects on persuasion.

As an alternative account, it has been suggested that moods may influence individuals' preferred processing style, and that persons in a good mood are more likely to engage in simplified, heuristic processing strategies, whereas persons in a bad mood may spontaneously engage in more effortful and detail-oriented analytic processing strategies (Schwarz, 1990; Schwarz and Bless, 1991; Schwarz and Bohner, 1990; see also Fiedler, 1988, Isen, 1987, and Kuhl, 1983, for related hypotheses). This prediction is derived from the assumption that "emotions exist for the sake of signalling states of the world that have to be responded to, or that no longer need response and action' (Frijda, 1988, p. 354).

If so, negative feelings may inform the individual that its current situation is problematic. They may therefore trigger processing styles that are adequate for analysing the problematic situation in order to determine adequate reactions. However, any mechanism that increases the accessibility of relevant procedural knowledge may also increase the likelihood that the respective procedures will be applied to other tasks to which they are applicable while the individual is in a negative affective state. Moreover, individuals in a negative state may be motivated to avoid erroneous decisions in a situation that is already characterized as problematic. As a result, a large body of literature indicates that individuals are more likely to use effortful, detail-oriented, analytical processing strategies spontaneously when they are put in a bad rather than in a good mood (see Schwarz, 1990, for a review).

Positive affective states, on the other hand, inform the individual that its current environment is a safe place. Accordingly, individuals in a good mood may be more likely to take risks and to use simple heuristics in information processing. Moreover, they may have better access to a variety of different procedural knowledge, given that no specific procedure is activated to cope with the current situation. In combination, this may facilitate the higher creativity that has been observed under elated 
mood, but may inhibit the spontaneous use of effortful analytic processing strategies, unless they are required by other active goals. Again, a considerable body of research supports this assumption (see Schwarz, 1990, for a review).

In line with a motivational rather than a capacity constraints account, research has shown that specific instructional sets may override mood effects on message processing. For example, Bless, Bohner et al. (1990, Experiment 1) observed that instructing good mood subjects to focus on the informational content of the message helped them overcome the processing deficits that were otherwise observed (for related findings see Innes and Ahrens, 1991). As it seems unlikely that serious capacity deficits could so easily be eliminated by a change in instructional set, this finding seems to support a motivational interpretation of mood effects on spontaneous processing style.

Thus, the available evidence concerning the role of motivational or capacity changes is mixed. The matter is additionally complicated by the fact that both Worth and Mackie's and Bless et al.'s manipulations are open for reinterpretations. Specifically, subjects could have interpreted the instruction that they may spend as much time as they wanted to evaluate the message (Mackie and Worth, 1989, p. 29) as indicating that the experimenter expects a careful analysis of message content, enhancing subjects' motivation to process. Conversely, Bless, Bohner et al.'s (1990) instruction to focus on message content may have reduced the required processing capacity by providing a clearer specification of the processing objectives.

In the two studies to be reported below, a different approach is used to test the assumption that differential motivation rather than differential capacity leads to the observed differences in message processing. We argue that capacity restrictions would be highly unlikely to mediate the observed effects if the previously obtained findings could be replicated under conditions that require only minimal cognitive capacity to begin with. Therefore, both experiments make use of very short mundane communications, in which only one argument (or none at all) is presented. A replication of the basic mood influence on the processing of message content under these conditions would suggest that changes in motivation are sufficient to produce the phenomenon.

\section{Affective states and the processing of context cues}

While the impact of recipients' mood on the processing of message content is welldocumented, there is only scarce evidence for mood influences on the processing of context information (i.e. 'peripheral cues' or 'heuristic cues' in the terminology of the ELM and HSM, respectively; Petty and Cacioppo, 1986a, b; Chaiken, 1987; Chaiken et al., 1989). Current theoretical approaches to persuasion share the assumption that reliance on context cues may increase as the systematic elaboration of message content decreases. Within the elaboration likelihood model (ELM), a general 'tradeoff between argument elaboration and the operation of peripheral cues' (Petty and Cacioppo, 1986a, p. 21) has been postulated. This implies that strong effects of context cues should only be obtained if the motivation or ability to process content information is low. Similarly, the 'heuristic-systematic model of persuasion' (HSM; Chaiken, 1987; Chaiken et al., 1989) provides for an antagonistic influence of content and non-content information, which has been discussed as the 'attenuation hypothesis' (Chaiken et al., 1989, p. 220). 
The latter model, however, explicitly emphasizes more complex conceptualizations of the interplay of content and context information in persuasion. Specifically, the HSM holds that systematic and heuristic processing may occur simultaneously under certain conditions. If an individual's motivation to process is high, heuristic cues may be considered as additional evidence when systematic processing alone does not provide sufficient information to assess the validity of a message. This may be due to either personal (e.g. high personal involvement) or situational factors (e.g. insufficient content information to form a judgment; see Chaiken et al., 1989, p. 226). In either case, individuals may consider the content of the message and context cues (e.g. the perceived reactions of others to the message) in combination to assess the validity of the message.

Assuming that negative mood increases the motivation to use detail-oriented, effortful processing strategies, while positive mood increases the probability of simplifying processing strategies, we may derive different predictions about the impact of affective states on the processing of context cues, depending on a number of conditions. Suppose that the content of a communication is sufficient to judge its validity, but that reliance on context cues promises to reduce cognitive effort and that a relevant heuristic is easily accessible to evaluate the implications of the context cues (Chaiken, 1987; Chaiken et al., 1989). Under these conditions, one should expect that persons in a positive mood are more likely than persons in a negative mood to base their judgment on the processing of these cues, at the expense of content elaboration. Individuals in a negative mood, on the other hand, should be more likely to engage in content elaboration, and may pay little attention to context cues, as they can evaluate the message on the basis of its content alone.

If, however, the content of the message is not sufficient to evaluate its validity, persons in a negative mood may be particularly likely to attend to context cues as an additional source of information as they strive to evaluate the validity of the communication. Thus, if the content of the message seems insufficient to form a judgement, negative moods may actually increase the processing of non-content cues, as part of an exhaustive, detail-oriented processing strategy.

Thus, if we combine the assumptions of the informative functions approach to affect and information processing with those of the HSM, the impact of mood on the processing of context cues should largely depend on two factors: First, the length and complexity of the persuasive message (bearing on the 'sufficiency criterion'), and second, the availability of relevant heuristics.

In two studies, Mackie and Worth (1989, Experiment 2; Worth and Mackie, 1987) manipulated source expertise as a context cue, independently of argument strength and subjects' mood. In these studies, subjects received a short description of the source, pertaining to its expertise. This description was followed by a message that contained eight (Mackie and Worth, 1989, Experiment 2) or nine (Worth and Mackie, 1987) arguments. In line with the ELM and the HSM's 'attenuation hypothesis', subjects in a positive mood tended to base their attitude judgments more on the expertise cue than did neutral mood subjects. Although it is questionable if a relevant judgmental heuristic (like 'experts can be trusted') was easily available in these experiments (for a more detailed discussion see Schwarz et al., 1991), the results are clearly compatible with the reasoning that context cues may be used as a means of reducing cognitive effort by individuals in a positive mood if confronted with a complex message. 
In Experiment 2 of the present paper, we shall, in contrast to the studies just described, examine mood influences on the processing of context information when a short message is presented, which is likely to provide insufficient information for subjects who are highly motivated to process systematically. As outlined above, it is predicted that under these circumstances, persons in a negative mood will rely more on context information than do persons in a positive mood. We will return to this issue after presenting Experiment 1, which was designed to replicate the basic finding that positive mood reduces the processing of message content, using a short and simple message.

\section{EXPERIMENT 1}

A field experiment was conducted that used a very simple persuasive message containing only one strong argument or no argument at all, which was presented to subjects in a non-manipulated or an elated mood. Furthermore, subjects' overt behaviour in response to the communication was observed instead of some judgmental measure, to provide a strong indicator of the message's persuasive impact. It was hypothesized that the behaviour of subjects in a neutral mood would reflect differences in message content, indicating that these subjects did in fact process systematically, whereas positive mood subjects' behaviour would be less affected by message content, replicating the previously obtained attitude change findings with overt behaviour as the dependent measure.

\section{Method}

\section{Subjects and procedure}

Seventy-eight adult users of a public telephone in the pedestrian area of a German city served as subjects. During the time allocated for the experiment, any person who found the phone booth empty, and thus did not have to wait in line, was included. The experiment was completed on two sunny summer days.'

\section{Independent variables}

In order to induce positive or neutral mood, either a coin (one German mark) or an onion was placed near the coin slot of the phone booth, for each subject to find. These objects were placed in random order and in such a fashion that it was virtually impossible not to notice them when trying to use the telephone. All subjects who found a coin took possession of it, whereas only one person who found an onion kept it. One third of the subjects was randomly assigned to a 'mood control' condition, which served exclusively to check the effectiveness of the mood manipulation (see below). The remaining subjects were randomly assigned to the two levels of a message strength factor. Before they could place their phone call, subjects were approached by a female confederate who was unaware of the subject's mood condition. The confederate asked for permission to advance in line and use the telephone

${ }^{1}$ As there is evidence for pronounced effects of weather on individuals' mood (e.g. Schwarz and Clore, 1983, Experiment 1), care was taken to avoid changes in weather during the course of the experiment. 
first, telling subjects in the 'strong message' condition that she had to contact her boss, who would only be in his office for another few minutes. In the 'weak message' condition, the confederate's request was not accompanied by any reason. Thus, the two independent variables constitute a 2 (positive versus neutral mood) $\times 2$ (strong versus weak message) factorial between-subjects design. The proportions of male and female subjects were about equal across conditions.

\section{Dependent variable}

Each subjects' behavioural reaction was coded as either complying (1) or not complying ( 0 ) with the confederate's request. Only immediate positive responses were coded as complying; any questions or arguments provided by the subject resulted in his or her behaviour being coded as not complying. This was done to ensure that no other information exchange except for the initial request itself would provide the cause of potential positive reactions.

\section{Mood manipulation check}

Of the 26 subjects who had been assigned to the 'mood control' condition, 13 had found a coin and 13 an onion. After these subjects had finished their telephone call, they were approached by a male confederate who was unaware of the subject's mood condition. The confederate identified himself as an associate of the local university, conducting a short survey on 'life in x-town'. All subjects agreed to answer three short questions as part of the survey. The first of these questions was designed to check the effectiveness of the mood manipulation: 'How do you feel right now, at this moment? - To answer, please give me a number between one and 10 . One means "very bad" and 10 means "very good"'. The confederate read the questions out loud and recorded the subject's response.

\section{Results}

\section{Mood}

The manipulation check revealed a marginally significant effect on subjects' reported mood of the type of object found. As expected, subjects who had found a coin reported feeling better $(M=7.5)$ than subjects who had found an onion $(M=6.0)$, $t(24)=1.52, p<0.075$, one-tailed. Although this effect may seem rather weak, it should be noted that these subjects had completed a telephone call in the time between finding the object and reporting their mood. Thus, mood differences in the experimental conditions, in which subjects were approached by the confederate immediately after they had found the object, are likely to be underestimated by the procedure adopted here.

\section{Contrast analysis}

In line with the hypothesis outlined above as well as with previous results, a specific two-way interaction of mood and message strength was predicted. Specifically, the largest proportion of compliance was expected for subjects who were in a neutral 
mood and were exposed to the strong message, the smallest proportion of compliance for subjects who were in a neutral mood and were exposed to the weak message. The two good mood conditions were expected to yield results in between these two extremes.

These considerations are reflected in the theoretically specified set of contrast weights shown in the lower part of Table 1 . The compliance data were analysed using contrast analysis for proportions (Rosenthal and Rosnow, 1985, pp. 46-59).

\section{Behavioural compliance}

The proportions of subjects who complied with the confederate's request are displayed in the upper part of Table 1. Inspection of the proportions in each cell reveals that, as predicted, the behaviour of subjects in a neutral mood was strongly influenced by message content: Whereas 92 per cent complied with the strong message, this was true only for 39 per cent of the subjects who were presented the weak message, resulting in a difference of 53 per cent. For subjects in a neutral mood, the effect of message strength was much less pronounced, with 75 per cent and 50 per cent compliance for the strong and weak message, respectively, resulting in a difference of 25 per cent.

Table 1. Proportion of subjects who complied with the confederate's request as a function of mood and message strength (above), and contrast weights used in data analysis (below)

\begin{tabular}{lcc}
\hline & \multicolumn{2}{c}{ Mood } \\
Message strength & Positive & Neutral \\
\hline (a) Results & & \\
Strong & 0.75 & 0.92 \\
& $(12)$ & $(13)$ \\
Weak & 0.50 & 0.39 \\
& $(14)$ & $(13)$ \\
(b) Contrast weights & & +1 \\
Strong & -1 & -3 \\
Weak & & \\
\hline
\end{tabular}

Numbers in parentheses are condition $n$ 's.

The planned contrast analysis yielded a highly significant result, $z=3.81, p<0.005$. Additional comparisons between the strong and weak versions of the message within each mood condition revealed a highly significant effect of message strength for subjects in a neutral mood, $z=3.50, p<0.002$, but not for subjects in a good mood, $z=1.37, p>0.15$.

\section{Discussion}

In summary, the basic finding of previous laboratory studies was replicated, using a behavioural measure in a natural setting. More importantly, the results support the hypothesis that recipient's mood influences the processing of message content even if the message presented is rather simple and does not require much processing capacity to begin with. Thus, it seems highly implausible that the observed mood effect was mediated by capacity deficits under positive mood. Rather, the results 
suggest that subjects in an elated mood may have been less motivated to analyse the presented message in any detail, reflecting that their affective state characterized the situation as non-problematic (Schwarz, 1990).

Moreover, a possible alternative explanation based on the potentially distracting nature of finding a coin can be ruled out. If anything, finding a coin in a telephone booth seems less surprising than finding an onion. Accordingly, subjects assigned to the neutral mood condition, who found an onion, should have been more distracted than subjects who found a coin, rendering a distraction-based account unlikely.

The present experiment also demonstrates that mood influences in persuasion are not restricted to attitude judgments, but are also reflected in overt behaviour. If one considers the seemingly irrelevant nature of the mood-inducing event used in this study, the potential importance of this phenomenon for everyday behaviour should become evident.

In the latter regard, we note that the present study bears some similarity to Langer's (1978, 1989; Langer, Blank \& Chanowtiz, 1978) work on the 'mindlessness' with which people engage in mundane behaviour. The behaviour of subjects in a positive mood might be characterized as 'mindless' according to Langer's conceptualization, whereas subjects in a neutral mood showed more 'mindfulness' in processing the request. Whereas Langer et al. (1978) emphasized stable features of the person (e.g. chronically accessible scripts) or the situation (e.g. low relevance) as the principal determinants of mindlessness, the results of the present experiment suggest that transient feeling states may have a similar impact.

\section{EXPERIMENT 2}

Although the behavioural data of Experiment 1 are consistent with the 'informative functions' approach to mood effects on persuasion, no direct evidence concerning the mediating role of message-related thoughts could be assessed, due to the nature of this field experiment. Accordingly, a conceptual replication and extension of Experiment 1 was designed to provide a more stringent test of the mediating role of subjects' cognitive responses. In addition, Experiment 2 tested diverging predictions derived from the ELM (Petty and Cacioppo, 1986a,b) and the HSM (Chaiken et al., 1989) concerning the processing of context cues under conditions of low versus high motivation, as outlined above.

\section{Method}

\section{Overview and design}

Subjects were recruited to participate individually in two ostensibly independent experiments on the topics of 'vocational aptitude' and 'communication'. In the allegedly 'first study', a positive or negative mood was induced through bogus feedback about the test result. While the subject was waiting for the 'second study' to begin, an interaction with a confederate was staged. The confederate asked subjects to donate money to a beneficial cause and supported this request with either one strong or one weak argument. Simultaneously, the confederate provided a salient context 
cue that was either strong or weak, namely a list of previous donors, containing few or many names.

These manipulations resulted in a 2 (good versus bad mood) $\times 2$ (strong versus weak message) $\times 2$ (strong versus weak context cue) factorial between-subjects design. The central dependent variables were subjects' overt behaviour, their cognitive responses, evaluations of message content, and recall of features of the situation.

\section{Subjects and procedure}

Seventy-three students of a West German university ( 30 female, 43 male) were randomly assigned to conditions and run in individual sessions. Upon arrival at the laboratory, each subject was paid 5 German Marks for participation. The data of nine subjects had to be excluded from the analysis. This was due to extraneous factors (e.g. language problems) for four subjects, while the other five expressed suspicion with respect to the bogus feedback or the authenticity of the persuasive communication. The drop-out rate was independent of experimental conditions. The data of 64 subjects ( 25 female, 39 male) remained in the analysis, eight in each experimental condition. The proportion of male and female subjects was approximately equal in all conditions.

\section{Mood induction}

Following procedures used by Bohner, Bless, Schwarz and Strack (1988), a good or bad mood was induced by giving subjects either positive or negative feedback about their results in an alleged 'Vocational Aptitudes Test'. Specifically, each subject had to solve 10 items of the 'Standard' and 'Advanced Progressive Matrices' tests of intelligence (Raven, 1958, 1962) ${ }^{2}$. To enhance the importance of the task, subjects were informed that the test was an excellent predictor of success in academic professions. The average performance in student populations was said to be six correct solutions. The task was explained in written instructions, and an example plus solution was provided. The experimenter made sure that the subject had understood the task. Then he presented each item on a card and checked the solution time with a stopwatch. The time limit for each item was 45 seconds. After this time, the subject had to mark his or her solution on a 'solution sheet'. To warrant the credibility of the feedback, subjects were encouraged to check a solution for each item, even if they were uncertain about it.

After completion of the task, the experimenter took the subject's solution sheet to a distant table, ostensibly to check the test result. In the positive mood conditions, he told the subject: 'Very good! These are eight correct solutions. This corresponds to the 86th percentile, which means that only 14 per cent of the students solve eight or more items correctly'. In the negative mood conditions, he informed the subject that he or she had solved only four items correctly, corresponding to the 14th percentile.

\footnotetext{
${ }^{2}$ The following items were administered in the same order as presented here. 'Bad mood' condition: Advanced Progressive Matrices (APM) Set 1I: 24, 21, 17; Standard Progressive Matrices (SPM) Set E: 12; APM Set II: 28, 13, 16, 23, 26, 19. 'Good mood' condition: APM Set II: 13, 14, 24; SPM Set E: 9; APM Set II: 17, 23, 26, 20, 16, 15.
} 


\section{Mood manipulation check}

Following the feedback, subjects answered a questionnaire related to the subjective experience of the test situation'. The first question was designed to check the efficiency of the mood manipulation and read: 'How do you feel now at this moment?' ( 1 = 'bad'; $9=$ 'good'). The remaining questions were fillers or pertained to sociodemographic variables. Following completion of the questionnaire, the experimenter announced that the first experiment was over and asked the subject to follow him to another laboratory, where the second experiment would be run. Outside of the second laboratory, he apologized and asked the subject to wait on a chair in the corridor because it would take a few more minutes to get things ready. Then he went into the laboratory, leaving the subject alone.

\section{Persuasive communication}

About 30 seconds later, the subject was approached by a female confederate, who was unaware of the subject's mood condition. The confederate wore a name tag that identified her as a member of a (fictitious) local organization supporting disabled students. She also carried a clipboard and a collecting-box. She greeted the subject and asked if she might talk to him or her for a moment. She then explained that her organization was conducting a collection on the campus.

Depending on experimental conditions, she said that the collected money would be used for the construction of ramps for wheelchairs at university buildings (strong argument) or for building a separate library for the disabled (weak argument), respectively. Pretesting had revealed a reliable difference in perceived argument strength for these two projects.

While presenting her argument, the confederate showed the subject a sheet with the headline 'List of Contributors' that contained either two (weak consensus cue) or 19 names (strong consensus cue). Pretesting of the two versions of the list in combination with a variety of collection purposes had indicated the effectiveness of this cue manipulation.

If a subject asked any questions, these were answered according to a pre-planned schema, which followed the general maxim not to give any additional detail information. After the subject had donated or had refused to do so, the confederate thanked, said good-bye, and left. About 1 minute later, the experimenter opened the door of the laboratory, apologized once again for the delay, and asked the subject in .

At this point, the subject was informed that the interaction with the money collector had been part of 'the second study', and additional dependent variables were assessed.

\section{Dependent variables}

Behaviour As the key behavioural measure of persuasive impact, it was recorded if a subject donated money (1) or did not (0). In addition, the amount donated was registered. It should be noted that all subjects had some money at their disposal, as they had been paid 5 German Marks (DM) for participation in advance. Moreover, this money had been handed out in small coins (one coin of DM 2, two coins of DM 1, one coin of DM 0.50, and five coins of DM 0.10). 
Cognitive responses Immediately after being informed that the interaction with the confederate was part of the study, each subject was given 3 minutes to list all thoughts that had come to mind during this interaction, on a sheet containing several boxes. Following the standard procedure proposed by Petty and Cacioppo (1986a, p. 38), subjects were encouraged to report any thought, even if it seemed irrelevant to them. Following the thought listing, subjects were asked to categorize these cognitive responses as being favourable, unfavourable, or neutral with respect to the donation request.

Recall Next, each subject was asked to recall as exactly and completely as possible all that the confederate said, the objects that she carried, the name of her organization, and the purpose of the collection.

Evaluation of purpose Finally, each subject had to rate the usefulness of the collection's purpose on a scale ranging from 1, 'not at all useful', to 9, 'very useful'.

Before leaving, subjects were probed for suspicion in an extensive post-experimental interview. Then they were thoroughly debriefed, were given back any money they had donated, and were dismissed.

\section{Results}

\section{Mood}

As expected, subjects who had been given negative feedback reported feeling significantly worse $(M=4.77)$ than subjects who had been given positive feedback $(M=6.53), \quad F(1,55)=18.76, p<0.0005^{3}$. In a $2 \times 2 \times 2$-analysis of variance (ANOVA), no other significant effects emerged, all $p>0.15$. Thus, we conclude that the mood manipulation was successful.

\section{Behaviour}

The percentage of donors and the mean amount donated in each condition are given in Table 2 .

Table 2. Proportion of donors and amount donated as a function of mood, strength of consensus cue, and argument quality

\begin{tabular}{lcccc}
\hline & \multicolumn{4}{c}{ Strength of consensus cue } \\
Mood & Positive & Negative & Positive & Negative \\
\hline Proportion of donors & & & & \\
$\quad$ Strong argument & 0.88 & 0.88 & 1.00 & 0.88 \\
$\quad$ Weak argument & 0.75 & 0.88 & 1.00 & 0.25 \\
Amount donated & & & & \\
$\quad$ Strong argument & 1.94 & 2.34 & 2.25 & 1.75 \\
$\quad$ Weak argument & 2.16 & 2.67 & 2.30 & 0.50 \\
\hline
\end{tabular}

The amount donated is given in German Marks.

A $2 \times 2 \times 2$-ANOVA revealed that a higher proportion of subjects in a positive $\operatorname{mood}(M=0.91)$ than of subjects in a negative mood $(M=0.72)$ contributed to

\footnotetext{
${ }^{3}$ One subject did not respond to the mood question.
} 
the collection, $F(1,56)=4.85, p<0.04$. This main effect was qualified, however, by a significant two-way interaction of mood and strength of the consensus cue, $F(1,56)=8.62, p<0.01$, and a significant three-way interaction, $F(1,56)=4.85$, $p<0.04$. No other significant effects emerged, all $p>0.14$.

Separate analyses at each level of the mood factor revealed that the behaviour of subjects in a good mood was neither affected by variations in message content, nor by variations in the non-content cue, all $p>0.12$. For subjects in a bad mood, on the other hand, both the main effects of argument strength and the consensus cue, as well as their interaction, reached statistical significance, $t(56)=2.59, p<0.02$, for each of these effects. Thus, under negative mood, the proportion of donors was greatly reduced when a weak argument was presented in combination with a weak consensus cue $(M=0.25)$, as compared to the conditions with either a strong argument $(M=0.88)$ or a strong cue $(\mathrm{M}=0.88)$.

Although the results for the amount of money donated show a similar pattern (cf. Table 2 ), there was only a marginally significant interaction of mood and strength of the consensus cue, $F(1,56)=3.50, p<0.07$, indicating that subjects in a negative mood tended to donate a higher amount when a strong $(M=2.51)$ rather than a weak cue $(M=1.13)$ was presented, whereas the amount of money donated by subjects in a good mood was independent of variations in the consensus cue ( $M$ 's $=2.05$ and 2.28 for the strong and weak cue, respectively).

\section{Cognitive responses}

The mean number of thoughts that subjects reported was $M=5.20$. Because systematic processing of content and context of the message should be reflected in effects of argument strength and variations of the consensus cue on the favourability of cognitive responses, for each subject, a favourability measure was computed by subtracting the proportion of unfavourable thoughts from the proportion of favourable thoughts. The possible range of this measure is from -1.00 to +1.00 , and its means are given in Table 3 .

Table 3. Mean favourability of cognitive responses* as a function of mood, strength of consensus cue, and argument quality

\begin{tabular}{lcccc}
\hline & \multicolumn{4}{c}{ Strength of consensus cue } \\
Mood & Positive & Negative & Positive & Neak \\
\hline Strong argument & 0.00 & -0.21 & 0.10 & 0.09 \\
Weak argument & -0.12 & -0.02 & 0.12 & -0.43 \\
\hline
\end{tabular}

*Proportion of favourable minus proportion of unfavourable thoughts. Possible range goes from -1.00 to +1.00 .

As can be seen in the table, the pattern of results parallels those of the behavioural data. A $2 \times 2 \times 2$-ANOVA revealed a nearly significant three-way interaction, $F(1,56)=3.82, p<0.06$. No other effects emerged, all $p>0.12$. Separate analyses showed that, analogous to the behavioural variables, good mood subjects' cognitive responses were unaffected by either argument strength or strength of the consensus cue, all $p>0.25$, whereas for bad mood subjects, favourability of thoughts reflected 
an interaction of argument strength and the consensus cue manipulation, $t(56)=2.31$, $p<0.03$. No other simple effects were detected, all $p>0.25$.

\section{Recall}

Recall protocols were coded by two independent judges for accuracy of three content categories: the purpose of the collection, the list of contributors, and the name of the collecting organization. All inconsistencies were resolved by discussion. For 'purpose' and 'organization', recall could be coded 0 ('no or incorrect recall'), 1 ('partially correct'), or 2 ('correct'). The agreement between judges was good, $r=0.83$ and 0.92 , respectively. For 'list', possible scores were 0 ('no recall') or 1 ('recall'); agreement between judges was perfect, $r=1.00$.

A $2 \times 2 \times 2$-ANOVA indicated that subjects in a negative mood tended to recall the purpose of the collection better $(M=1.56)$ than did subjects in a positive mood $(M=1.16), F(1,56)=3.93, p<0.06$, all other $p>0.29$. Similar, but nonsignificant patterns emerged for the other two recall measures (see Table 4).

Table 4. Recall for details of the situation as a function of mood

\begin{tabular}{lccc}
\hline Mood & $\begin{array}{c}\text { Donation's } \\
\text { purpose }\end{array}$ & $\begin{array}{c}\text { Dependent variable } \\
\text { Name of } \\
\text { organization }\end{array}$ & $\begin{array}{c}\text { List of } \\
\text { contributors }\end{array}$ \\
\hline Positive & 1.16 & 1.22 & 0.53 \\
Negative & 1.56 & 1.56 & 0.63 \\
\hline
\end{tabular}

The possible range for the variables in the left and middle columns is 0 to 2 , for the variable in the right column 0 to 1 , with higher values indicating better recall.

\section{Evaluation of purpose}

Not surprisingly, building wheelchair ramps was rated as being more useful $(M=7.81)$ than building a separate library $(M=6.19), F(1,55)=9.87, p<0.005^{4}$. More importantly, a marginally significant two-way interaction of mood and argument strength emerged, $F(1,55)=3.40, p<0.07$, indicating that subjects in a negative mood strongly differentiated between the strong $(M=8.44)$ and weak purpose $(M=5.88), t(17.0)=3.90, p<0.002$, whereas subjects in a positive mood did not $\left(M ' s=7.19\right.$ and 6.53 , respectively), $t(21.1)=0.80, p>0.40 .^{5}$

\footnotetext{
${ }^{4}$ One subject did not respond to the question concerning the evaluation of the collection's purpose.

${ }^{5}$ Separate variance estimates were used in these simple effects $t$-tests because of inhomogeneity of variances. Two additional marginally significant two-way interactions were obtained for the evaluation of purpose: In the 'weak cue'-condition, subjects tended to differentiate more between the strong and weak purpose $(M ' s=8.38$ versus 5.75$)$ than in the 'strong cue'-condition $(M$ 's $=7.25$ versus 6.67$), F(1,55)=3.86$, $p<0.06$ ). Furthermore, subjects in a good mood tended to rate any purpose as more useful when the weak $(M=7.38)$ rather than the strong cue $(M=6.33)$ was presented, while this pattern was reversed for subjects in a bad mood $(M$ 's $=6.75$ versus 7.56$), F(1,55)=3.17, p<0.09$. No other effects emerged, all $F<1$.
} 


\section{Correlational analyses}

Correlational analyses were conducted to explore the relationship of subjects' cognitive responses and overt behaviour. As shown in Table 5, behavioural measures of persuasion were significantly correlated with the favourability of cognitive responses and with the evaluation of the collection's purpose under bad mood conditions, but not under good mood conditions. Moreover, tests of differences in the correlations obtained under the two mood conditions indicated that the correlations of both behavioural measures and the evaluation of the collection's purpose were significantly higher under bad than under good mood conditions ( $c f$. Table 5).

Table 5. Correlations of behavioural measures with cognitive responses and evaluations of purpose as a function of mood

\begin{tabular}{lccc}
\hline & \multicolumn{2}{c}{ Mood } & $z$-test for \\
& Positive & Negative & difference \\
\hline Willingness to donate & & & \\
$\quad \times$ Favourability of cognitive responses & 0.30 & $0.47^{*}$ & 0.76 \\
$\quad \times$ Evaluation of collection's purpose & 0.03 & $0.64^{*}$ & $2.77^{*}$ \\
Amount donated & & & \\
$\quad \times$ Favourability of cognitive responses & 0.24 & $0.36 \dagger$ & 0.50 \\
$\quad \times$ Evaluation of collection's purpose & -0.15 & $0.47^{*}$ & $2.52 \dagger$ \\
\hline
\end{tabular}

${ }^{*} p<0.01 ; \nmid p<0.05$. All probabilities reported are two-tailed. $N=32$ for each mood condition.

\section{Discussion}

The results of Experiment 2 provide a replication and extension of the findings of Experiment 1. Once more, pronounced mood effects on subjects' overt behaviour were observed, following a short and uncomplicated communication. Furthermore, the results clearly support the notion that individuals who are in a negative mood may carefully evaluate both content and context information when processing a persuasive communication, whereas individuals in a positive mood were likely to remain unaffected by either message content or context cues.

Through the analysis of subjects' cognitive responses, evaluations, and memory for details, Experiment 2 also provided information about the processes that mediated the impact of affective state on the behavioural responses. These data suggest that the behaviour of individuals in a negative mood clearly depended on the favourability of the thoughts that came to mind during the persuasive communication, as well as on the perceived usefulness of the cause. In contrast, the behaviour of subjects in a positive mood showed only moderate or no association with cognitive responses or evaluations, respectively. Finally, negative mood subjects' slightly superior recall of relevant details is compatible with the assumption that they paid closer attention to the particular aspects of the situation.

The finding of a simultaneous impact of message content and context cues under negative mood, in combination with the absence of such an impact under positive mood, supports the assumption of the HSM that highly motivated individuals may 'access and scrutinize all informational input for its relevance and importance to 
their judgment task, and integrate all useful information in forming their judgements' (Chaiken et al., 1989, p. 212, italics added).

The results cannot be accounted for adequately, however, by the ELM's postulate of a 'tradeoff between argument elaboration and the operation of peripheral cues' (Petty and Cacioppo, 1986a, p. 21). Although the authors of the ELM point out that there may be instances when both arguments and peripheral cues are operative (e.g. Petty and Cacioppo, 1984), the model clearly predicts that any factor that increases elaboration likelihood, including bad mood, should enhance argument impact and decrease cue impact, while the reverse should be true for any factor decreasing elaboration likelihood, including good mood. Thus, the ELM cannot account for the simultaneous decrease of both argument and cue processing under good mood, as compared to bad mood, that was observed in Experiment 2.

It should be noted, however, that the ELM was originally conceptualized to explain attitude change when a message containing numerous arguments is presented. As documented by a large body of research (e.g. Chaiken, 1980; Petty, Cacioppo and Goldman, 1981; Petty et al., 1983), under these circumstances, a 'tradeoff' between content and cues is more likely to be observed than under the conditions realized in the present study. We shall return to this issue in the general discussion.

\section{GENERAL DISCUSSION}

The results of the reported studies provide clear support for the notion that the influence of mood on the processing of persuasive communications is mediated by differences in processing style, as predicted by the informative functions approach (Schwarz, 1990). It seems highly unlikely that the observed effects are due to capacity differences, as the situations in these two studies required only minimal capacity to begin with. This does not imply, however, that capacity constraints under positive mood are generally implausible - they may be observed in different types of situations, depending on the type of event that elicited affect, and on affect intensity ( $c f$. Taylor, in press). The present experiments suggest, however, that motivational influences of mood are sufficient to produce differences in information processing, even if rather mild mood inductions are used, as was the case in Experiment 1.

\section{Behavioural decisions and the impact of good mood: the mediating role of scripts}

An apparent inconsistency between the findings of Experiment 1 and Experiment 2 deserves further attention. Whereas the predicted interaction of affective state and argument quality was obtained in both experiments, good mood subjects in Experiment 2 were generally more likely to donate money, consistent with a large body of research on affect and helping behaviour (see Schaller and Cialdini (1990) for a review). In contrast, being in a good mood did not per se influence subjects' willingness to let a confederate advance in line in Experiment 1 . We propose that this reflects the impact of affective states on 'mindless' behaviour.

According to Langer et al. (1978), 'mindless' behaviour is due to subjects' reliance on overlearned scripts that are applicable to the situation at hand (Schank and Abelson, 1977). In general, this reliance should be more pronounced under the heuristic processing conditions elicited by elated moods. However, the specific behavioural 
decision depends on the implications of the most accessible script. In Experiment 2 , a 'money collection script' may have been available to subjects, including that the collector explains the purpose of the collection (which is legitimate by default), and the target person donates a small amount. Complying to this script did not interfere with any of the subjects' ongoing activities in Experiment 2, as they were waiting for the next experiment to begin. In Experiment 1, on the other hand, a 'telephone call script' was likely to be activated before the confederate stated her request. Complying with the request would therefore have interfered with the ongoing sequence of scripted behaviour. As a result, reliance on the most accessible script would have opposite consequences for subjects' reactions in the two studies: Whereas pursuing the activated script would lead to noncompliance in Experiment 1, the reverse would be true for Experiment 2.

These conjectures are compatible with the notion that affective states serve informative functions (Schwarz, 1990). From this point of view, it would be highly dysfunctional to rely on overlearned scripts for persons whose negative affective state informs them that their current situation may be problematic. Conversely, if a positive affective state indicates that the current situation is safe, script-guided behaviour would promise high efficiency. Future studies should explicitly manipulate the accessibility of different scripts to test the prediction that behavioural decisions are more scriptguided under good than under bad moods.

\section{Anticipation of judgment as a determinant of context impact}

In contrast to the present studies, all previous experiments on mood and persuasion have presented written (Bless et al. 1990; Innes and Ahrens, 1991; Mackie and Worth, 1989; Worth and Mackie, 1987) or taped messages (Bless, Bohner et al., 1990) in laboratory settings. Accordingly, the recipients were usually aware from the outset that some kind of judgment or evaluative response (though not necessarily about the message's topic) may be expected from them, motivating subjects to pay some attention to relevant information. This may have contributed to the finding that individuals in a positive mood made some use of non-content information in order to form a judgment under conditions that confronted them with a rather complex message (Mackie and Worth, 1989; Worth and Mackie, 1987). In contrast, good mood subjects in the present Experiment 2, who did not anticipate that a decision or judgment would be required, were neither influenced by variations in message content nor by variations in context cues. This suggests that individuals in an elated mood only pay attention to context cues when currently active processing goals require them to do so, much as Bless et al. (1990, Experiment 1) observed for message content.

\section{Mood and the use of message content and context cues: Some conjectures}

The above considerations suggest that future research on affect and persuasion might benefit from a more explicit treatment of message complexity, script or schema accessibility, and expected processing objectives. We assume that persons in a positive mood, whose affective state informs them that their current environment is safe (Schwarz, 1990), are generally less motivated to pay close attention to content or to non-content information and to elaborate on its implications in any detail. As 
a result, they may be neither influenced by message content nor by context cues, as was the case in Experiment 2. Rather, their judgments or behaviours may be a function of pre-existing schemata or scripts. If they do anticipate that they may have to form a judgment, on the other hand, they may simplify this task by relying on non-content cues, provided that a relevant schema is easily accessible. This assumption is compatible with Petty and Cacioppo's (1986a,b) 'peripheral route to persuasion', and equivalent to the heuristic processing mode described by Chaiken (1980, 1987; Chaiken et al., 1989). It is also in line with empirical findings (Mackie and Worth, 1989; Worth and Mackie, 1987).

Finally, systematic processing of message content is only expected under elated moods when recipients are explicitly instructed to pay attention to the quality of the arguments (Bless et al., 1990, Experiment 1) or when the issue is of extreme importance.

Recipients in a negative mood, on the other hand, whose affective state informs them that the situation may be problematic (Schwarz, 1990), are assumed to pay close attention to incoming information and to elaborate on its implications, choosing what Petty and Cacioppo (1986a,b) termed the 'central route to persuasion'. As a result, their judgements and behavioural decisions reflect an impact of message content, independently of the expected processing objectives. If message content is insufficient to form a judgment, however, these subjects may turn to the implications of context cues in addition to message content, as suggested by the 'sufficiency criterion' of the HSM (Chaiken et al., 1989). Under these circumstances, attitude judgments or behavioural decisions are a function of message content and context information, as was observed in the bad mood conditions of Experiment 2.

In summary, the present conjectures and findings indicate that how we feel may strongly influence how we react to attempts to persuade us. Extending previous laboratory research, the reported studies demonstrated that a complex interplay of recipients' mood, message quality, and contextual cues determines persuasive success in everyday settings, reflecting that individuals in an elated mood are less likely to engage in detail-oriented systematic information processing than individuals in neutral or mildly depressed moods.

\section{REFERENCES}

Bless, H., Bohner, G., Schwarz, N. and Strack, F. (1990). 'Mood and persuasion: A cognitive response analysis', Personality and Social Psychology Bulletin, 16: 331-345.

Bless, H., Mackie, D. and Schwarz, N. (1990). 'Mood effects on encoding and judgmental processes in persuasion'. Manuscript under review.

Bohner, G., Bless, H., Schwarz, N. and Strack, F. (1988). 'What triggers causal attributions? The impact of valence and subjective probability', European Journal of Social Psychology, 18: $335-345$.

Chaiken, S. (1980). 'Heuristic versus systematic information processing and the use of source versus message cues in persuasion', Journal of Personality and Social Psychology, 39: 752-766.

Chaiken, S. (1987). 'The heuristic model of persuasion'. In: Zanna, M. P., Olson, J. M. and Herman, C. P. (Eds) Social Influence: The Ontario Symposium, Vol. 5, Erlbaum, Hillsdale, N.J., pp. 3-39.

Chaiken, S., Axsom, D., Yates, S. M., Wilson, D., Hicks, A. and Liberman, A. (1988). 'Heuristic processing of persuasive messages: The role of temporary and chronic sources of accessibility'. Unpublished manuscript, New York University.

Chaiken, S., Liberman, A., Eagly, A. H. (1989). 'Heuristic and systematic information process- 
ing within and beyond the persuasion context'. In: Uleman, J. S. and Bargh, J. A. (Eds) Unintended Thought: Limits of Awareness, Intention and Control, Guilford, New York.

Eagly, A. H. and Chaiken, S. (In press). 'The psychology of attitudes'. Fort Worth, TX: Harcourt Brace Jovanovich.

Fiedler, K. (1988). 'Emotional mood, cognitive style, and behavior regulation'. In: Fiedler, K. and Forgas, J. (Eds) Affect, Cognition and Social Behavior, Hogrefe, Toronto, pp. 100119.

Frijda, N. H. (1988). 'The laws of emotion', American Psychologist, 43: 349-358.

Innes, J. M. and Ahrens, C. R. (1991). 'Positive mood, processing goals, and the effects of information on evaluative judgment'. In: Forgas, J. (Ed.) Emotion and Social Judgment, Pergamon, Oxford.

Isen, A. M. (1987). 'Positive affect, cognitive processes, and social behaviour'. In: Berkowitz, L. (Ed.) Advances in Experimental Social Psychology, Vol. 20, Academic Press, San Diego, pp. 203-253.

Kiesler, S. B. and Mathog, R. (1968). 'The distraction hypothesis in attitude change', Psychological Reports, 23: 1123-1133.

Kuhl, J. (1983). 'Emotion, Kognition and Motivation: II. Die funktionale Bedeutung der Emotionen für das problemlösende Denken und für das konkrete Handeln', Sprache und Kognition, 4: 228-253.

Langer, E. J. (1978). 'Rethinking the role of thought in social interaction'. In: Harvey, F. H., Ickes, W. and Kidd, R. F. (Eds) New Directions in Attribution Research, Vol. 2, Erlbaum, Hillsdale, NJ, pp. 35-58.

Langer, E. J. (1989). 'Minding matters: The consequences of mindlessness-mindfulness'. In: Berkowitz, L. (Ed.) Advances in Experimental Social Psychology, Vol. 22, Academic Press, New York, pp. 137-173.

Langer, E. J., Blank, A. and Chanowitz, B. (1978). 'The mindlessness of ostensibly thoughtful action: The role of "placebic" information in interpersonal interaction', Journal of Personality and Social Psychology, 36, 635-642.

Mackie, D. and Worth, L. T. (1989). 'Processing deficits and the mediation of positive affect in persuasion', Journal of Personality and Social Psychology, 57: 27-40.

Matlin, M. and Stang, D. (1979). The Polyanna Principle, Schenkman, Cambridge, Mass.

Petty, R. E. and Cacioppo, J. T. (1981). Attitudes and Persuasion: Classic and Contemporary Approaches, Brown, Dubuque, Iowa.

Petty, R. E. and Cacioppo, J. T. (1984). 'Source factors and the elaboration likelihood model of persuasion', Advances in Consumer Research, 11: 668-672.

Petty, R. E. and Cacioppo, J. T. (1986a). Communication and Persuasion. Central and Peripheral Routes to Attitude Change, Springer, New York.

Petty, R. E. and Cacioppo, J. T. (1986b). 'The elaboration likelihood model of persuasion'. In: Berkowitz, L. (Ed.) Advances in Experimental Social Psychology, Vol. 19, Academic Press, New York, pp. 124-203.

Petty, R. E., Cacioppo, J. T. and Goldman, R. (1981). 'Personal involvement as a determinant of argument-based persuasion', Journal of Personality and Social Psychology, 41: $847-855$

Petty, R. E., Cacioppo, J. T. and Kasmer, J. A. (1988). 'The role of affect in the elaboration likelihood model of persuasion'. In: Donohue, L., Sypher, H. E. and Higgins, E. T. (Eds) Communication, Social Cognition, and Affect, Erlbaum, Hillsdale, N.J., pp. 117-146.

Petty, R. E., Cacioppo, J. T. and Schumann, D. (1983). 'Central and peripheral routes to advertising effectiveness: The moderating role of involvement', Journal of Consumer Research, 10: 134-148.

Raven, J. C. (1958). Standard Progressive Matrices. Sets A, B, C, D, and E, Lewis, London.

Raven, J. C. (1962). Advanced Progressive Matrices. Set II. 1962 Revision, Lewis, London.

Rosenthal, R. and Rosnow, R. L. (1985). Contrast Analysis, Cambridge University Press, Cambridge.

Schaller, M. and Cialdini, R. B. (1990). 'Happiness, sadness, and helping: A motivational integration'. In: Higgins, E. T. and Sorrentino, R. (Eds) Handbook of Motivation and Cognition: Foundations of Social Behavior, Vol. 2, Guilford, New York, pp. 265-296. 
Schank, R. and Abelson, R. (1977). Scripts, Plans, Goals, and Understanding, Erlbaum, Hillsdale, N.J.

Schwarz, N. (1990). 'Feelings as information: Informational and motivational functions of affective states'. In: Sorrentino, and Higgins, (Eds) Handbook of Motivation and Cognition: Foundations of Social Behavior, Vol. 2, Guilford Press, New York, pp. 527-561.

Schwarz, N. and Bless, B. (1991). 'Happy and mindless, but sad and smart? The impact of affective states on analytic reasoning'. In: Forgas, J. (Ed.) Emotion and Social Judgment, Pergamon, London, pp. 55-72.

Schwarz, N., Bless, H. and Bohner, G. (1991). 'Mood and persuasion: Affective states influence the processing of persuasive communications'. In: Zanna, M. (Ed.) Advances in Experimental Social Psychology, Vol. 24, pp. 161-199.

Schwarz, N. and Bohner, G. (1990). 'Stimmungseinflüsse auf Denken und Entscheiden'. In: Maas, P. and Weibler, J. (Eds) Börse und Psychologie, Deutscher Institutsverlag, Köln, pp. $162-189$.

Schwarz, N. and Clore, G. L. (1983). 'Mood, misattribution and judgments of well-being: Informative and directive functions of affective states', Journal of Personality and Social Psychology, 45: 513-523.

Taylor, S. E. (In press). 'The asymmetrical effects of positive and negative events: The mobilization-minimization hypothesis', Psychological Bulletin.

Worth, L. T. and Mackie, D. M. (1987). 'Cognitive mediation of positive affect in persuasion', Social Cognition, 5: 76-94. 